\title{
HERDABILIDADE E GANHO GENÉTICO EM CARACTERES DO FRUTO DO MARACUJAZEIRO-DOCE ${ }^{1}$
}

\author{
MARICELMA SIMIANO JUNG ${ }^{2}$, EDUARDO ALANO VIEIRA ${ }^{3}$, ADEMAR BRANCKER $^{4}$, RUBENS ONOFRE NODARI $^{5}$
}

RESUMO-O maracujazeiro-doce, Passiflora alata Curtis, é uma planta frutífera que vem despertando interesse econômico principalmente para o consumo in natura. Contudo, precisam ser superados alguns entraves tecnológicos em relação ao seu cultivo, tais como a ausência de cultivares que apresentem frutos com alto rendimento de polpa, resistência mecânica e elevado teor de sólidos solúveis totais. Nesse sentido, este trabalho teve por objetivo estimar a herdabilidade $\left(\mathrm{h}^{2}\right)$ e o ganho genético esperado com a seleção, para os caracteres peso do fruto, peso da polpa, espessura da casca, sólidos solúveis totais e rendimento de polpa em maracujazeiro-doce, por meio da avaliação de 36 cruzamentos envolvendo seis genitores femininos e seis masculinos. Os resultados obtidos evidenciaram uma ampla variação na magnitude dos valores da $h^{2}$ entre os cruzamentos e a predominância de efeitos gênicos de aditividade no controle genético dos caracteres. Assim, é necessário levar em consideração o grande efeito do fator cruzamento na estimativa da $\mathrm{h}^{2}$, bem como a realização da seleção direta na maioria das progênies avaliadas em razão de que os efeitos aditivos predominaram no controle da maioria dos caracteres estudados.

Termos para indexação: Passiflora alata Curtis, fruteira nativa do Brasil, ganho genético, melhoramento genético.

\section{HERITABILITY AND GENETIC GAIN IN FRUIT OF SWEET PASSION FRUIT CHARACTERES}

ABSTRACT - The sweet passion fruit, Passiflora alata Curtis, is a fruit tree that has been gaining economic importance because their fruits can be consumed in natura due to its unique flavor. However, some technologic obstacles need to be overcome in order to allow plantation in large scale, such as the absence of cultivars producing fruits with high pulp output, mechanic resistance in its skin, and high levels of soluble solids. In this context, this work was carried out to estimate the inheritability $\left(\mathrm{h}^{2}\right)$ and the genetic gain as expected selection response for the traits: weigh of the fruit, weight of the pulp, thickness of the skin, Brix degree and pulp output. To achieve the goals, it was used F1 progenies from 36 crosses involving six females and six males' half sib genotypes. The results showed a broad variation in the $\mathrm{h}^{2}$ values across crosses and the predominance of the additive gene effects in the genetic control of the evaluated traits. Therefore, it its necessary to take into account the substantial effect of the cross factor in the $\mathrm{h}^{2}$ estimative and the direct selection in the majority of the progenies because the additive gene effects are predominant in the majority of the studied traits.

Index Terms: Passiflora alata Curtis, Brazilian native fruit, genetic gain, plant breeding.

\section{INTRODUÇÃO}

O maracujazeiro-doce é uma fruteira nativa do Brasil, cujos frutos evidenciam elevado potencial para consumo in natura, em função de seu sabor apreciado pelos consumidores (Braga et al., 2005). A espécie é alógama e expressa elevada variabilidade genética (Aukar et al., 2002; Melletti et al., 2003; Farias et al., 2005), passível, portanto, de ser explorada para fins de melhoramento genético, por meio do desenvolvimento de cultivares. Em razão do consumo in natura do fruto, alguns caracteres merecem atenção especial, tais como, sabor, aparência, peso do fruto, peso de polpa, rendimento de polpa, resistência da casca, sólidos solúveis totais, resistência a pragas e moléstias, entre outros. Nesse contexto, fica evidente a necessidade de estudos direcionados à melhoria da qualidade dos frutos do maracujazeiro, bem como a elevação da produtividade e a resistência a pragas e doenças (Ruggiero et al., 1996).

O conhecimento da variabilidade fenotípica dos caracteres de importância agronômica é imprescindível para o melhorista quanto da definição dos métodos de melhoramento, seleção de genitores, escolha dos locais para a condução dos testes de rendimento, definição do número de repetições e predição dos ganhos por seleção. A variação entre os fenótipos em uma população surge das diferenças médias entre os genótipos

1 (Trabalho 054-07). Recebido: 02-03-2007. Aceito para publicação: 24-08-2007.

${ }^{2}$ Mestre em Recursos Genéticos Vegetais, Universidade do Sul de Santa Catarina, Av. José Acácio Moreira, no 787. C.P. 370 - CEP: $88704-900$, Tubarão, SC, Brasil. E-mail: msimiano@unisul.br.

${ }_{3}^{3}$ Doutor em Fitomelhoramento, Pesquisador da Embrapa Cerrados, Planaltina, DF. E:mail: vieiraea@cpac.embrapa.br.

${ }^{4}$ Engenheiro Agrônomo, Pesquisador da Epagri, Empresa de Pesquisa Agropecuária e Extensão Rural de Santa Catarina. Rod. SC 446 Km 19, C.P. 49 , CEP 88840-000, Urussanga, SC, Brasil. E-mail: brancher@epagri.rct-sc,br.

${ }^{5}$ Doutor em Genética, Professor Titular da Universidade Federal de Santa Catarina, Programa de Pós-graduação em Recursos Genéticos Vegetais, C.P. 476, CEP. 88040-900, Florianópolis, SC, Brasil. E-mail: nodari@cca.ufsc.br 
e da variação ambiental. As variações de ambiente podem ofuscar as de natureza genética e quanto maior for a proporção da variabilidade decorrente do ambiente em relação à variabilidade total, mais difícil será selecionar genótipos de forma efetiva.

Como para a maioria das espécies de interesse agronômico, o melhoramento do maracujazeiro-doce também envolve a caracterização e a avaliação de germoplasma, estudo da herança de caracteres, seleção de genitores para hibridação e melhoramento intra e interpopulacional (Pereira et al., 2005). Estudos a respeito da herança de caracteres relacionados aos frutos do maracujazeiro-doce são necessários e constituem uma das maiores contribuições da genética quantitativa ao melhoramento genético, por permitirem a predição dos ganhos obtidos com a seleção. Por meio destas informações, é possível orientar de maneira mais efetiva um programa de melhoramento, predizer o sucesso do esquema seletivo adotado e decidir, com base científica, as técnicas alternativas que podem ser mais eficazes (Cruz \& Regazzi, 1997).

A proporção herdável da variabilidade total é designada herdabilidade (Falconer \& Mackay, 1996). Essa é uma medida da influência genética e informa que parte da variação da população em um fenótipo pode ser atribuída à variação no genótipo, possibilitando estimativas como o ganho genético esperado com a seleção (Allard, 1999). A herdabilidade pode ser estimada no sentido amplo como sendo a proporção da variabilidade observada ocasionada por efeitos dos genes ou herdabilidade no sentido restrito, que é a proporção da variabilidade observada ocasionada somente por efeitos aditivos dos genes (Carvalho et al., 2001). Para fins de melhoramento genético, a herdabilidade no sentido restrito é a mais adequada, uma vez que considera somente a aditividade, que é a porção herdável da variância genética, que, em última instância, é o que pode ser passado de geração a geração por seleção.

Os objetivos do presente trabalho foram estimar, em maracujazeiro-doce, a herdabilidade dos caracteres peso do fruto, peso de polpa, espessura da casca, sólidos solúveis totais e rendimento de polpa, bem como estimar o ganho genético esperado com a seleção.

\section{MATERIAL E MÉTODOS}

O experimento foi conduzido na Estação Experimental da Epagri de Urussanga (SC), situada a $28^{\circ} 31^{\prime}$ latitude sul e $49^{\circ} 19^{\prime}$ longitude oeste e a uma altitude de $48 \mathrm{~m}$. Os genitores de Passiflora alata Curtis utilizados no estudo foram obtidos em uma coleção de 1.250 genótipos meio-irmãos pertencentes à Epagri, oriundas da hibridação de 25 genitores femininos com um genitor masculino. Nessa população, foram selecionados 12 genótipos fenotipicamente contrastantes para os caracteres rendimento de polpa, peso médio do fruto e espessura da casca (Jung, 2003). Os 12 genótipos selecionados foram intercruzados (polinização manual), sendo seis utilizados como genitores femininos (mães, denominados de M1 a M6) e seis como genitores masculinos (pais, denominados de P1 a P6), totalizando 36 cruzamentos dirigidos. Visando a garantir a acurácia dos cruzamentos dirigidos, as flores das plantas femininas foram cobertas antes da antese e emasculadas antes da polinização.

Para cada um dos 36 cruzamentos, foram geradas sementes em quantidade tal que assegurasse a obtenção de, pelo menos, 32 plântulas segregantes por cruzamento. As sementes foram postas para germinar em casa de vegetação, e, posteriormente, as mudas foram transplantadas para o campo. Em cada cova, foram alocadas duas mudas e, após o total estabelecimento das mesmas, foi mantida uma planta por cova, restando, então, 576 plantas $\mathrm{F}_{1}$ s segregantes e 192 plantas multiplicadas por estacas que correspondiam aos genitores, totalizando 768 plantas no experimento. As plantas foram mantidas no espaçamento de $1 \mathrm{~m}$ entre plantas e $2,5 \mathrm{~m}$ entre linhas e conduzidas no sistema de espaldeira.

Os caracteres aferidos por meio da avaliação de 10 frutos por planta foram peso do fruto (PF) em g, peso da polpa (PP) em $\mathrm{g}$, espessura da casca (EC) em mm (utilizando-se de um paquímetro), sólidos solúveis totais (SST) em graus Brix (utilizando-se de um refratômetro) e rendimento de polpa (RP) por meio da razão entre o peso da polpa e o peso total do fruto.

A herdabilidade de cada caráter, em cada cruzamento, foi estimada no sentido amplo, por meio da equação:

$$
h^{2}=\frac{\sigma_{G}^{2}}{\sigma_{F}^{2}}
$$

Onde: i) $h^{2}=$ herdabilidade no sentido amplo; ii) $\sigma_{\mathrm{F}}^{2}=$ componente da variância fenotípica, estimado por meio da variância das progênies $\mathrm{F}_{1 \mathrm{~s}}$; iii) $\sigma^{2} \mathrm{e}=$ componente da variância ambiental, estimado por meio da variância existente para os caracteres aferidos nos genitores multiplicados vegetativamente, e iv) $\sigma_{G}^{2}=$ componente da variância genotípica, estimado por meio de: $\sigma_{\mathrm{G}}^{2}=\sigma_{\mathrm{F}}^{2}-\sigma^{2}$ e. Cabe ressaltar que todo valor negativo de herdabilidade foi considerado como nulo (zero), o que, conforme Linch \& Walsh (1998), é um indicativo de baixa variância genética.

Após a estimativa da $h^{2}$ no sentido amplo, foi empregado o teste $\mathrm{t}$ de comparação de médias, a $5 \%$ de probabilidade de erro, seguindo o procedimento descrito por Beiguelman (2002), a fim de comparar a média dos genitores com a média das progênies $\mathrm{F}_{1 \mathrm{~s}}$. Ou seja, quando existe a predominância de efeitos aditivos no controle de um caráter, em determinado cruzamento, a média dos genitores não difere da média da progênie e, em caso da existência de efeitos não-aditivos (dominância e/ou epistasia) no controle de um caráter, a média dos genitores difere da média da progênie $F_{1}$ (Allard, 1999).

O ganho genético esperado quando da seleção foi estimado por meio da equação:

$\Delta_{G}=i \cdot h^{2} \cdot \sigma_{F}$

Onde: i) $\Delta_{\mathrm{G}}=$ ganho genético esperado; ii) i= intensidade de seleção $(10 \%)=1,76$, e iii) $\sigma_{\mathrm{F}}=$ desvio-padrão da variância fenotípica, estimado por meio da raiz quadrada do componente $\sigma_{\mathrm{F}}^{2}$.

\section{RESULTADOS E DISCUSSÃO}

A herdabilidade no sentido amplo do caráter peso do 
fruto (PF) oscilou muito entre os cruzamentos, variando de 50,94\%, no cruzamento M6xP1, a $0 \%$, em nove cruzamentos (Tabela 1). Cabe ressaltar que todo valor negativo de herdabilidade foi considerado como nulo (zero). Em todos os cruzamentos, a média dos genitores não diferiu da média da progênie pelo teste $t$, a 5\% de probabilidade de erro para o caráter PF. Esse resultado é um indicativo de que a herdabilidade no sentido amplo, estimada para esse caráter, é muito próxima da herdabilidade no sentido restrito, uma vez que não ocorreram efeitos da dominância ou epistasia, que fariam com que a média da progênie diferisse da média dos genitores (Allard, 1999; Carvalho et al., 2001).

$\mathrm{O}$ caráter peso de polpa (PP) revelou valores de herdabilidade nos cruzamentos que variaram de $40,24 \%$, no cruzamento M1xP6, a $0 \%$, constatado em três cruzamentos (Tabela 1). Comparando-se as médias dos cruzamentos com a média dos genitores por meio do teste $t$, verificou-se que, na maioria dos cruzamentos, a média da progênie não diferiu estatisticamente da média dos pais. Logo, a herdabilidade no sentido amplo está também muito próxima da herdabilidade no sentido restrito, pois os efeitos de dominância ou epistasia ou inexistem ou são de magnitudes reduzidas (Allard, 1999; Carvalho et al., 2001). Apenas os cruzamentos M2xP1, M3xP3, M3xP5 e M5xP2 evidenciaram médias diferentes da de seus genitores, o que é um indicativo de que, nesses cruzamentos, o caráter PP é governado tanto por genes de efeitos aditivos como por genes que exibem algum grau de dominância ou epistasia. Dessa forma, para esses cruzamentos, a parte herdável da variância genética é menor do que a herdabilidade no sentido amplo estimada.

Para o caráter espessura da casca (EC), os valores estimados da herdabilidade no sentido amplo variaram de 38,08\%, no cruzamento M5xP6, a $0 \%$, observada em cinco cruzamentos (Tabela 1). Provavelmente, a herdabilidade estimada no sentido amplo está muito próxima da herdabilidade no sentido restrito, uma vez que, na maioria dos cruzamentos, o teste $\mathrm{t}$ não detectou diferenças significativas, a 5\% de probabilidade de erro entre a média dos genitores e a média da progênie, o que é um indicativo da predominância de efeitos gênicos de aditividade no controle desse caráter, na maioria dos cruzamentos avaliados. Somente os cruzamentos M1xP2, M2xP1, M2xP4, M3xP2, M5xP4 e M6xP6 revelaram genes com algum grau de dominância ou epistasia controlando o caráter, evidenciando que, nesses cruzamentos, a parte herdável da variância genética é inferior à herdabilidade no sentido amplo estimada.

Os valores estimados da herdabilidade, no sentido amplo do caráter sólidos solúveis totais (SST), variaram nos cruzamentos de $27,78 \%$, no cruzamento $\mathrm{M} 1 \times \mathrm{xP} 1$, a $0 \%$, revelado em 12 cruzamentos (Tabela 1). Na comparação entre médias dos cruzamentos com a média dos respectivos genitores, por meio do teste $t$, não foram detectadas diferenças significativas, com exceção dos cruzamentos M1xP1, M1xP3, M1xP4, M1xP5 e M1xP6. Assim, conclui-se que a herdabilidade no sentido amplo está muito próxima da herdabilidade no sentido restrito, com exceção de cinco famílias que envolvem a mãe 1 , onde a herdabilidade no sentido amplo estimada difere da herdabilidade no sentido restrito (fração herdável da variância genética).

Os valores obtidos para a herdabilidade do caráter rendimento de polpa (RP) variaram de $49,13 \%$, no cruzamento M2xP6, a 0\%, observado em dois cruzamentos (Tabela 1). Comparando-se as médias dos cruzamentos com as médias dos respectivos genitores, por meio do teste $t$, observou-se que, em todos os casos, a média dos filhos não diferiu estatisticamente da média dos pais. Assim, pode-se admitir que a herdabilidade, no sentido amplo, está muito próxima da herdabilidade no sentido restrito. Portanto, nesses cruzamentos, a ação gênica de aditividade é a mais importante no controle genético desse caráter.

Quanto à estimativa do ganho genético esperado $\left(\Delta_{\mathrm{G}}\right)$, se a intensidade de seleção for fixada em $10 \%$, espera-se: i) para PF $\Delta_{G}$, entre $23,51 \%$ e $1,90 \%$; ii) para PP $\Delta_{G}$, entre $19,10 \%$ e $1,50 \%$; iii) para $\mathrm{EC} \Delta_{\mathrm{G}}$, entre $-12,40 \%$ e $-1,10 \%$; iv) para SST $\Delta_{\mathrm{G}}$, entre $4,50 \%$ e $0,20 \%$, e v) para RP $\Delta_{\mathrm{G}}$ entre $1,4 \%$ e $0,4 \%$ (Tabela 2 ). Esses resultados evidenciaram que o ganho genético esperado com a seleção depende do cruzamento avaliado e que será tão maior quanto maior a variância de origem genética na população segregante, e em especial, para os genitores avaliados neste trabalho, que são meios-irmãos.

Os resultados obtidos para as estimativas da herdabilidade no sentido amplo e do ganho genético esperado para os cinco caracteres aferidos dão uma idéia da importância do conhecimento da herdabilidade de um caráter antes de se iniciar o processo de melhoramento genético. Para todos os caracteres, houve uma ampla variação na magnitude dos valores estimados da $\mathrm{h}^{2}$ entre os cruzamentos, o que revela que essa estimativa, em muitos casos, é dependente do cruzamento em questão. Essa dependência do cruzamento ocorre em função de dos genitores apresentarem genes distintos controlando esses caracteres ("background genético" divergente) e, assim, é esperado que a $\mathrm{h}^{2}$ seja dependente do cruzamento. Se for levado em consideração que o maracujazeiro-doce evidencia elevada variabilidade genética, esse quadro pode ser ampliado. Dessa forma, é possível inferir que, em maracujazeiro, possivelmente, a seleção massal é a mais eficiente para caracteres de fácil mensuração, que possuam razoável herdabilidade e predominância dos efeitos aditivos, levando-se em conta o cruzamento em questão. Nesse sentido, Maluf et al. (1989) relataram a ocorrência de valores elevados para a herdabilidade para os caracteres precocidade e peso médio de frutos em maracujazeiro-amarelo, evidenciando a grande importância da variância genética. Já Negreiros et al. (2004) detectaram, em maracujazeiro-amarelo, herdabilidades de $44,68 \%$ para resistência à verrugose e de 56,53\% para o caráter vigor, e Viana (2001) relatou a ocorrência de herdabilidades variando de 95,93\% a $97,29 \%$ para número de frutos. Esses autores sugeriram que são esperados ganhos genéticos elevados por meio da seleção direta para esses caracteres, uma vez que o ambiente não evidencia grande influência na expressão dos mesmos. De acordo com Allard (1999), a predominância dos efeitos aditivos é um dos fatores para a eficiência da seleção massal.

$\mathrm{Na}$ maioria dos cruzamentos avaliados, houve uma predominância da ação gênica de aditividade no controle dos caracteres, o que é um indicativo de que, em maracujazeiro-doce, a maior parte da variação genética para os caracteres PF, PP, EC, SST e RP seja herdável e passível de ser transmitida à progênie. 
Entretanto, é relevante ressaltar que os genitores utilizados para a obtenção das progênies aqui estudadas são meios-irmãos e, dessa forma, são aparentados, exibindo uma base genética estreita, fato que pode ter contribuído para a diminuição dos desvios promovidos pelos efeitos da dominância nos cruzamentos e ter ampliado o efeito da aditividade (Allard, 1999;
Carvalho et al., 2001). Portanto, como os efeitos aditivos predominaram para a maioria dos caracteres, é possível a realização da seleção direta ou seleção massal para esses caracteres, nestas progênies segregantes, para os caracteres aqui avaliados.

TABELA 1- Média $(\mu)$, variância $\left(\sigma^{2}\right)$ e herdabilidade no sentido amplo $\left(h^{2}\right)$ dos caracteres peso do fruto (PF), peso da polpa (PP), espessura da casca (EC), sólidos solúveis totais (SST) e rendimento de polpa (RP), em 36 progênies $\mathrm{F}_{1}$ e nos 12 genitores de maracujazeiro-doce, sendo seis femininos (M) e seis masculinos (P).

\begin{tabular}{|c|c|c|c|c|c|c|c|c|c|c|c|c|c|c|c|}
\hline \multirow{3}{*}{$\begin{array}{c}\text { Cruzamentos } \\
(\mathbf{M x P})\end{array}$} & \multicolumn{15}{|c|}{ Caracteres } \\
\hline & \multicolumn{3}{|c|}{ PF } & \multicolumn{3}{|c|}{ PP } & \multicolumn{3}{|c|}{ EC } & \multicolumn{3}{|c|}{ SST } & \multicolumn{3}{|c|}{$\mathbf{R P}$} \\
\hline & $\mu(\mathrm{g})$ & $\sigma^{2}$ & $\mathbf{h}^{2}$ & $\mu(\mathrm{g})$ & $\sigma^{2}$ & $\mathbf{h}^{2}$ & $\mu(\mathrm{mm})$ & $\sigma^{2}$ & $\mathbf{h}^{2}$ & $\mu(\%)$ & $\sigma^{2}$ & $\mathbf{h}^{2}$ & $\mu(\%)$ & $\sigma^{2}$ & $\mathbf{h}^{2}$ \\
\hline $1 \times 1$ & 213,39 & 1640,61 & 17,16 & 66,05 & 182,96 & 1,63 & 9,3 & 2,36 & 24,96 & $18,0^{*}$ & 2,77 & 27,78 & 31,01 & 18,51 & 25,99 \\
\hline $1 \times 2$ & 217,56 & 1673,90 & 18,81 & 67,09 & 231,48 & 22,25 & $9,4^{*}$ & 1,99 & 11,27 & 17,8 & 2,09 & 4,52 & 30,91 & 22,23 & 38,36 \\
\hline $1 \times 3$ & 203,70 & 1443,07 & 5,82 & 61,55 & 192,18 & 6,35 & 9,5 & 2,53 & 20,14 & $17,8^{*}$ & 2,02 & 1,10 & 30,46 & 20,26 & 32,40 \\
\hline $1 \times 4$ & 215,31 & 2065,07 & 34,19 & 64,46 & 187,41 & 3,96 & 9,4 & 2,30 & 23,10 & $17,9^{*}$ & 2,14 & 6,66 & 30,19 & 13,33 & 0 \\
\hline $1 \times 5$ & 217,38 & 1554,49 & 12,57 & 64,72 & 220,79 & 18,49 & 9,6 & 2,21 & 19,98 & $18,0^{*}$ & 1,92 & 0 & 29,81 & 20,03 & 31,61 \\
\hline $1 \times 6$ & 214,54 & 1865,97 & 27,17 & 65,46 & 301,18 & 40,24 & 10,1 & 2,13 & 16,93 & $18,0^{*}$ & 2,57 & 22,30 & 30,50 & 25,09 & 45,41 \\
\hline $2 \times 1$ & 205,83 & 1352,30 & 0 & $63,33^{*}$ & 193,47 & 6,97 & $9,1^{*}$ & 1,85 & 4,44 & 17,7 & 2,24 & 10,89 & 30,94 & 16,39 & 16,39 \\
\hline $2 \times 2$ & 213,25 & 1653,06 & 17,79 & 66,71 & 201,46 & 10,66 & 9,5 & 2,57 & 31,07 & 18,3 & 2,66 & 24,69 & 31,48 & 20,09 & 31,80 \\
\hline $2 \times 3$ & 210,46 & 1687,65 & 19,47 & 65,98 & 195,26 & 7,82 & 9,3 & 2,07 & 14,31 & 17,9 & 1,73 & 0 & 31,77 & 17,41 & 21,31 \\
\hline $2 \times 4$ & 203,73 & 1010,41 & 0 & 64,29 & 182,88 & 1,59 & $9,1^{*}$ & 1,62 & 0 & 18,1 & 2,27 & 11,79 & 31,61 & 21,66 & 26,76 \\
\hline $2 \times 5$ & 225,19 & 1942,16 & 30,02 & 72,16 & 251,93 & 28,56 & 10,2 & 2,48 & 28,72 & 18,3 & 1,95 & 0 & 32,21 & 18,79 & 27,09 \\
\hline $2 \times 6$ & 213,51 & 2123,15 & 35,99 & 65,94 & 266,21 & 32,39 & 9,1 & 2,08 & 15,06 & 18,3 & 2,01 & 0,48 & 31,02 & 26,93 & 49,13 \\
\hline $3 \times 1$ & 220,46 & 1814,91 & 25,12 & 65,91 & 219,98 & 18,18 & 10,0 & 2,14 & 17,18 & 18,0 & 2,19 & 8,71 & 30,02 & 19,23 & 28,76 \\
\hline $3 \times 2$ & 208,00 & 1813,60 & 25,06 & 63,04 & 220,09 & 18,22 & $9,0^{*}$ & 1,74 & 0 & 18,0 & 1,83 & 0 & 30,41 & 21,94 & 37,54 \\
\hline $3 \times 3$ & 211,61 & 964,47 & 0 & $61,26^{*}$ & 112,14 & 0 & 8,9 & 1,87 & 5,73 & 17,8 & 2,17 & 7,62 & 29,12 & 18,32 & 25,24 \\
\hline $3 \times 4$ & 219,81 & 1723,90 & 21,16 & 69,31 & 217,25 & 17,16 & 9,1 & 1,60 & 0 & 17,9 & 2,40 & 16,55 & 31,72 & 21,42 & 36,05 \\
\hline $3 \times 5$ & 215,34 & 763,17 & 0 & $67,03 *$ & 120,25 & 0 & 9,0 & 2,48 & 28,72 & 18,0 & 1,75 & 0 & 31,01 & 10,48 & 0 \\
\hline $3 \times 6$ & 199,52 & 1281,78 & 11,51 & 65,09 & 205,48 & 12,41 & 9,8 & 2,52 & 29,69 & 17,9 & 2,21 & 9,47 & 32,56 & 17,84 & 2320 \\
\hline $4 \times 1$ & 216,24 & 1810,79 & 24,83 & 68,19 & 249,39 & 27,83 & 10,0 & 2,32 & 23,56 & 18,1 & 2,03 & 1,33 & 31,63 & 21,46 & 36,17 \\
\hline $4 \times 2$ & 206,69 & 1100,47 & 0 & 63,19 & 181,04 & 0,59 & 9,7 & 2,62 & 32,34 & 18,0 & 2,08 & 3,76 & 30,60 & 13,89 & 1,40 \\
\hline $4 \times 3$ & 223,18 & 1773,02 & 23,35 & 70,72 & 230,65 & 21,97 & 9,9 & 2,61 & 32,17 & 18,2 & 2,04 & 1,8 & 31,90 & 17,71 & 22,62 \\
\hline $4 \times 4$ & 211,50 & 1742,43 & 22,00 & 64,61 & 222,41 & 19,08 & 8,9 & 1,89 & 6,51 & 18,1 & 2,32 & 13,93 & 30,69 & 16,22 & 15,53 \\
\hline $4 \times 5$ & 218,54 & 1210,12 & 0 & 68,11 & 187,29 & 3,90 & 9,1 & 2,05 & 13,80 & 18,3 & 1,61 & 0 & 31,21 & 16,57 & 17,33 \\
\hline $4 \times 6$ & 221,98 & 1877,00 & 27,59 & 68,38 & 267,75 & 32,78 & 8,9 & 1,97 & 10,37 & 18,1 & 1,89 & 0 & 31,00 & 26,30 & 47,91 \\
\hline $5 \times 1$ & 216,96 & 2263,97 & 39,97 & 67,82 & 269,02 & 33,10 & 9,3 & 2,38 & 25,54 & 18,0 & 2,57 & 22,09 & 31,43 & 21,97 & 37,65 \\
\hline $5 \times 2$ & 205,56 & 1815,02 & 25,12 & $67,10^{*}$ & 225,91 & 20,33 & 9,6 & 2,39 & 25,95 & 18,3 & 1,75 & 0 & 32,72 & 15,80 & 13,30 \\
\hline $5 \times 3$ & 204,50 & 2116,84 & 35,80 & 64,44 & 242,12 & 25,67 & 9,3 & 2,01 & 12,10 & 18,0 & 2,42 & 17,22 & 31,76 & 22,74 & 39,75 \\
\hline $5 \times 4$ & 208,28 & 1841,43 & 26,20 & 61,93 & 189,61 & 5,08 & $9,1^{*}$ & 1,76 & 0 & 18,2 & 1,90 & 0 & 30,00 & 16,03 & 14,55 \\
\hline $5 \times 5$ & 214,47 & 1192,37 & 0 & 67,20 & 252,87 & 28,83 & 8,7 & 2,11 & 15,93 & 18,0 & 1,84 & 0 & 31,26 & 27,02 & 49,30 \\
\hline $5 \times 6$ & 216,66 & 1354,98 & 0 & 64,24 & 170,33 & 0 & 9,1 & 2,86 & 38,08 & 18,0 & 1,96 & 0 & 29,75 & 15,80 & 13,31 \\
\hline $6 \times 1$ & 216,41 & 2770,39 & 50,94 & 66,53 & 276,03 & 34,80 & 9,3 & 1,82 & 2,50 & 17,9 & 2,42 & 17,19 & 31,01 & 21,04 & 34,88 \\
\hline $6 \times 2$ & 217,87 & 1584,59 & 14,23 & 64,18 & 210,31 & 14,42 & 9,7 & 2,59 & 31,66 & 17,9 & 2,29 & 12,50 & 29,54 & 19,04 & 28,04 \\
\hline $6 \times 3$ & 210,05 & 1280,82 & 0 & 64,93 & 201,01 & 10,46 & 9,1 & 2,15 & 17,57 & 18,3 & 2,06 & 2,92 & 30,96 & 19,30 & 29,01 \\
\hline $6 \times 4$ & 226,06 & 1463,46 & 7,13 & 68,71 & 216,96 & 17,04 & 9,7 & 2,34 & 24,40 & 17,9 & 1,98 & 0 & 30,47 & 20,59 & 33,47 \\
\hline $6 \times 5$ & 221,00 & 1643,69 & 17,32 & 67,26 & 244,76 & 26,47 & 9,2 & 2,53 & 29,95 & 18,2 & 2,26 & 11,31 & 30,48 & 17,31 & 20,84 \\
\hline $6 \times 6$ & 217,04 & 1495,66 & 9,13 & 66,96 & 206,89 & 13,01 & $9,1^{*}$ & 1,73 & 0 & 18,0 & 2,14 & 6,60 & 30,84 & 17,53 & 21,85 \\
\hline \multicolumn{16}{|l|}{ Genitores } \\
\hline M1 & 200,55 & 927,93 & & 62,33 & 174,22 & & 10,00 & 1,80 & & 18,04 & 2,04 & & 31,19 & 16,29 & \\
\hline M2 & 219,35 & 1333,45 & & 69,38 & 200,48 & & 9,57 & 2,05 & & 18,18 & 1,67 & & 31,76 & 17,42 & \\
\hline M3 & 221,99 & 795,20 & & 72,10 & 142,32 & & 9,13 & 1,39 & & 17,91 & 2,10 & & 32,34 & 11,58 & \\
\hline M4 & 214,48 & 2005,51 & & 62,33 & 217,27 & & 9,58 & 1,37 & & 18,04 & 1,50 & & 28,97 & 16,52 & \\
\hline M5 & 219,19 & 1568,02 & & 68,14 & 152,44 & & 9,02 & 1,71 & & 18,07 & 1,91 & & 31,17 & 16,28 & \\
\hline M6 & 214,82 & 1262,00 & & 69,60 & 197,91 & & 8,96 & 2,10 & & 18,24 & 2,10 & & 32,35 & 15,51 & \\
\hline P1 & 219,73 & 1789,92 & & 64,12 & 231,59 & & 10,17 & 1,74 & & 17,66 & 2,16 & & 29,09 & 11,91 & \\
\hline P2 & 213,61 & 1678,22 & & 63,66 & 175,77 & & 9,61 & 2,32 & & 17,95 & 2,50 & & 29,86 & 9,66 & \\
\hline P3 & 205,44 & 921,73 & & 56,94 & 128,70 & & 8,71 & 0,94 & & 18,00 & 1,61 & & 27,62 & 8,83 & \\
\hline P4 & 205,15 & 1225,10 & & 58,97 & 195,85 & & 10,16 & 2,43 & & 17,91 & 2,14 & & 28,73 & 17,47 & \\
\hline P5 & 232,31 & 1888,79 & & 71,20 & 216,39 & & 9,37 & 1,83 & & 17,34 & 2,52 & & 30,68 & 13,55 & \\
\hline P6 & 217,93 & 912,86 & & 58,67 & 126,80 & & 10,47 & 1,58 & & 18,26 & 1,75 & & 26,83 & 9,35 & \\
\hline
\end{tabular}

*média do cruzamento significativamente diferente da média dos genitores, a 5\% de probabilidade de erro, pelo teste $\mathrm{t}$. 
TABELA 2- Herdabilidade no sentido amplo $\left(\mathrm{h}^{2}\right)$, ganho genético esperado $\left(\Delta_{\mathrm{G}}\right)$ e porcentagem de ganho genético $\left(\Delta_{\mathrm{G}}\right)$ quando do emprego de uma intensidade de seleção de $10 \%$, para os caracteres peso do fruto (PF), peso da polpa (PP), espessura da casca (EC), sólidos solúveis totais (SST) e rendimento de polpa (RP), em 10 progênies de maracujazeiro-doce.

\begin{tabular}{ccccc}
\hline Caráter & Cruzamento & $\mathbf{h}^{\mathbf{2}} \mathbf{( \% )}$ & $\boldsymbol{\Delta}_{\mathbf{G}}$ & $\mathbf{\Delta}_{\mathbf{G}} \mathbf{( \% )}$ \\
\hline PF & M6xP1 & $54,95 \%$ & $50,90 \mathrm{~g}$ & $23,51 \%$ \\
PF & M1xP3 & $5,82 \%$ & $3,80 \mathrm{~g}$ & $1,90 \%$ \\
PP & M1xP6 & $40,24 \%$ & $12,30 \mathrm{~g}$ & $19,10 \%$ \\
PP & M1xP4 & $3,96 \%$ & $0,90 \mathrm{~g}$ & $1,50 \%$ \\
EC & M5xP6 & $38,08 \%$ & $-1,10 \mathrm{~mm}$ & $-12,40 \%$ \\
EC & M2xP1 & $4,40 \%$ & $-0,10 \mathrm{~mm}$ & $-1,10 \%$ \\
SST & M1xP1 & $27,78 \%$ & $0,80{ }^{\circ} \mathrm{Brix}$ & $4,50 \%$ \\
SST & M4xP3 & $1,80 \%$ & $0,04{ }^{\circ} \mathrm{Brix}$ & $0,20 \%$ \\
RP & M2xP6 & $49,13 \%$ & $4,50 \mathrm{~g}$ & $14,40 \%$ \\
RP & M4xP2 & $1,40 \%$ & $0,09 \mathrm{~g}$ & $0,40 \%$ \\
\hline
\end{tabular}

\section{CONCLUSÕES}

1- Verificou-se entre os diferentes cruzamentos ampla variação nas estimativas de herdabilidade e ganho genético em diferentes caracteres dos frutos de maracujazeiro-doce. Para os caracteres peso do fruto, peso da polpa, espessura da casca, sólidos solúveis totais e rendimento de polpa, os valores de herdabilidade variaram de zero até $50,94 \%, 34,80 \%, 38,08 \%, 27,78 \%$ e 49,30, respectivamente.

2- $O$ fato de que foi detectada a predominância de efeitos gênicos aditivos em relação aos desvios de dominância, indica perspectivas reais para a eficiência da seleção direta ou seleção massal para a melhoria dessas características do maracujazeirodoce.

\section{AGRADECIMENTOS}

Os autores agradecem à UNISUL, pelo apoio a M.S.J; à EPAGRI, pelo material vegetal e campo experimental; ao CNPq, pela bolsa a R.O.N., e aos revisores anônimos que muito contribuíram para o aperfeiçoamento do manuscrito.

\section{REFERÊNCIAS}

ALLARD, R.W. Principies of plant breeding. $2^{\text {nd }}$ ed. New York: John Wiley \& Sons, 1999. 254p.

AUKAR, A.P.; LEMOS, E.G.M.; OLIVEIRA, J.C. Genetic variations among passion fruit species using RAPD markers. Revista Brasileira de Fruticultura, Jaboticabal, v.24, n.3, p.738-740, 2002.

BEIGUELMAN, B. Curso prático de bioestatística. 5. ed. Ribeirão Preto: FUNPEC, 2002.272p.

BRAGA, M.F.; JUNQUEIRA, N.T.V.; FALEIRO, F.G.; BELLON, G.; JUNQUEIRA, K.P. Maracujá-doce: melhoramento genético e germoplasma. In: FALEIRO, F.G.; JUNQUEIRA, N.T.V.; BRAGA, M.F. Maracujá germoplasma e melhoramento genético. Planaltina: Embrapa Cerrados, 2005. cap. 24, p.601-616.
CARVALHO, F.I.F.; SILVA, S.A.; KUREK, A.J.; MARCHIORO, V.S. Estimativas e implicações da herdabilidade como estratégia de seleção. Pelotas: UFPEL, 2001.99p.

CRUZ, C.D.; REGAZZI, A.J. Modelos biométricos aplicados ao melhoramento genético. 2. ed. Viçosa: UFV, 1997. 390p.

FALCONER, D.S.; MACKAY, T.F.C. Introduction to quantitative genetics. Essex: Longman, 1996. 464p.

FARIAS, M.A.A.; FARIA, G.A.; CUNHA, M.A.P.; PEIXOTO, C.P.; SOUSA, J.S. Caracterização física e química de frutos de maracujá amarelo de ciclos de seleção massal estratificada e de populações regionais. Magistra, Cruz das Almas, v.17, n.2, p.8387,2005 .

JUNG, M.S. Análise da base genética do rendimento de polpa e resistência da casca do maracujazeiro-doce (Passiflora alata) e seleção de progênies superiores. 2003. 98f. Dissertação (Mestrado em Recursos Genéticos Vegetais) - Universidade Federal de Santa Catarina, Florianópolis, 2003.

LINCH, M.; WALSH, B. Genetics and analysis of quantitative traits. Sunderland: Sinauer Associates, 1998. 980p.

MALUF, W.R; SILVA, J.R.; GRATTAPAGLIA, D.; TOMABRAGHINI, M.; COTE, R. D.; MACHADO, M. A; CALDAS, L. S. Genetic gains via clonal selection in passion fruit Passiflora edulis Sims. Revista Brasileira de Genética, Ribeirão Preto, v.12, n.4, p.833-84, 1989.

MELETTI, L.M.M.; BERNACCI, L.C.; SOARES-SCOTT, M.D.; AZEVEDO FILHO, A.; MARTINS, A.L.M. Variabilidade genética em caracteres morfológicos, agronômicos e citogenéticos de populações de maracujazeiro-doce (Passiflora alata Curtis). Revista Brasileira de Fruticultura, Jaboticabal, v.25, n.2, p.275$278,2003$.

NEGREIROS, J.R.S.; BRUCKNER, C.H.; CRUZ, C.D.; SIQUEIRA, D.L.; PIMENTEL, L.D. Seleção de progênies de maracujazeiroamarelo vigorosas e resistentes à verrugose (Cladosporium cladosporioides). Revista Brasileira de Fruticultura, Jaboticabal, v.26, n.2, p.272-275, 2004.

PEREIRA, M.G.; PEREIRA, T.N.S.; VIANA, A.P. Marcadores moleculares aplicados ao melhoramento genético do maracujazeiro. In: FALEIRO, F.G.; JUNQUEIRA, N.T.V.; BRAGA, M.F. Maracujá germoplasma e melhoramento genético. Planaltina: Embrapa Cerrados, 2005. cap. 11, p. 277-292.

RUGGIERO, C.; SÃO JOSÉ,A.R.; VOLPE, C.A.; OLIVEIRA, J.C.; DURIGAN, J.F.; BAUMGARTNER, J.G.; SILVA, J.R.; MAKAMURA, K.I.; FERREIRA, M.E.; KAVATI, R.; PEREIRA, V.P. Maracujá para exportação: aspectos técnicos da produção. Brasília: Embrapa, 1996. 64p. 
VIANA, A.P. Correlações e parâmetros genéticos em populações de maracujazeiro-amarelo (Passiflora edulis f. flavicarpa) e diversidade molecular no gênero Passiflora. 2001. 98f. Tese
(Doutorado em Produção Vegetal) - Universidade Estadual do Norte Fluminense, Campos do Goytacazes, 2001. 